NASA/TM-2000-210318

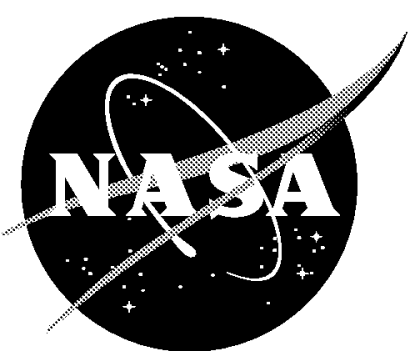

\title{
DSMC Simulations of Shock Interactions About Sharp Double Cones
}

James N. Moss

Langley Research Center, Hampton, Virginia 


\section{The NASA STI Program Office ... in Profile}

Since its founding, NASA has been dedicated to the advancement of aeronautics and space science. The NASA Scientific and Technical Information (STI) Program Office plays a key part in helping NASA maintain this important role.

The NASA STI Program Office is operated by Langley Research Center, the lead center for NASA's scientific and technical information. The NASA STI Program Office provides access to the NASA STI Database, the largest collection of aeronautical and space science STI in the world. The Program Office is also NASA's institutional mechanism for disseminating the results of its research and development activities. These results are published by NASA in the NASA STI Report Series, which includes the following report types:

- TECHNICAL PUBLICATION. Reports of completed research or a major significant phase of research that present the results of NASA programs and include extensive data or theoretical analysis. Includes compilations of significant scientific and technical data and information deemed to be of continuing reference value. NASA counterpart of peer-reviewed formal professional papers, but having less stringent limitations on manuscript length and extent of graphic presentations.

- TECHNICAL MEMORANDUM. Scientific and technical findings that are preliminary or of specialized interest, e.g., quick release reports, working papers, and bibliographies that contain minimal annotation. Does not contain extensive analysis.

- CONTRACTOR REPORT. Scientific and technical findings by NASA-sponsored contractors and grantees.
- CONFERENCE PUBLICATION. Collected papers from scientific and technical conferences, symposia, seminars, or other meetings sponsored or co-sponsored by NASA.

- SPECIAL PUBLICATION. Scientific, technical, or historical information from NASA programs, projects, and missions, often concerned with subjects having substantial public interest.

- TECHNICAL TRANSLATION. Englishlanguage translations of foreign scientific and technical material pertinent to NASA's mission.

Specialized services that complement the STI Program Office's diverse offerings include creating custom thesauri, building customized databases, organizing and publishing research results ... even providing videos.

For more information about the NASA STI Program Office, see the following:

- Access the NASA STI Program Home Page at http://www.sti.nasa.gov

- E-mail your question via the Internet to help@sti.nasa.gov

- Fax your question to the NASA STI Help Desk at (301) 621-0134

- Phone the NASA STI Help Desk at (301) 621-0390

- Write to: NASA STI Help Desk NASA Center for AeroSpace Information 7121 Standard Drive Hanover, MD 21076-1320 
NASA/TM-2000-210318

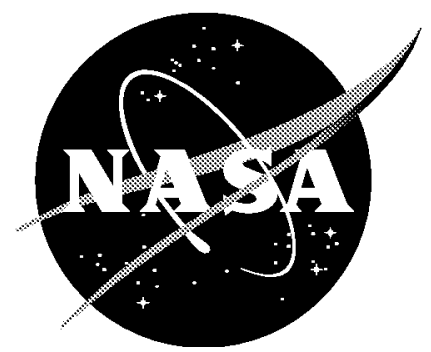

\section{DSMC Simulations of Shock Interactions About Sharp Double Cones}

James N. Moss

Langley Research Center, Hampton, Virginia

National Aeronautics and

Space Administration

Langley Research Center

Hampton, Virginia 23681-2199 
Available from:

NASA Center for AeroSpace Information (CASI)

7121 Standard Drive

Hanover, MD 21076-1320

(301) 621-0390
National Technical Information Service (NTIS) 5285 Port Royal Road

Springfield, VA 22161-2171

(703) 605-6000 


\title{
DSMC Simulations of Shock Interactions about Sharp Double Cones
}

\author{
James N. Moss \\ NASA Langley Research Center, Hampton, VA 23681-2199, USA
}

\begin{abstract}
This paper presents the results of a numerical study of shock interactions resulting from Mach 10 flow about sharp double cones. Computations are made by using the direct simulation Monte Carlo (DSMC) method of Bird. The sensitivity and characteristics of the interactions are examined by varying flow conditions, model size, and configuration. The range of conditions investigated includes those for which experiments have been or will be performed in the ONERA R5Ch low-density wind tunnel and the Calspan-University of Buffalo Research Center (CUBRC) Large Energy National Shock (LENS) tunnel.
\end{abstract}

\section{INTRODUCTION}

Shock/shock and shock/boundary layer interactions continue to receive considerable attention because of their impact on the performance and design requirements of hypersonic vehicles. Augmented aerothermal loads and degraded control surface effectiveness are often unavoidable because of these interactions. Therefore, techniques that accurately predict these interactions and their consequences are required for vehicle design. Careful comparisons and analysis of computational and experimental results are essential in establishing confidence in the prediction tools. The current study provides numerical results for hypersonic low-density flows where the resulting database can be used for guidance and comparison with future experiments.

The current investigation focuses on Mach 10, low Reynolds number $\left(\operatorname{Re}_{\infty, d}<45000\right)$ flows. For the doublecone models investigated, the first cone half angle is $25^{\circ}$, while the second cone half angle is either $55^{\circ}$ or $65^{\circ}$. These double cone geometries produce strong shock interactions because the attached shock from the first cone interacts with the detached bow shock from the second cone. Also, the outer shocks are modified by the separation and reattachment shocks where the extent of flow separation is significant for several combinations of model size and flow conditions. Two of the flow conditions investigated are for experiments that have been or will be performed. The calculations for the $25^{\circ} / 65^{\circ}$ model are for nominal flow conditions produced by the ONERA R5Ch wind tunnel. Calculations for a range of model diameters are made that encompass the diameter for which an experiment is scheduled. Calculations performed for the $25^{\circ} / 55^{\circ}$ model configuration include those for the model size and both actual and nominal low Reynolds number test conditions produced in the CUBRC LENS tunnel. Also, the flow about a smaller scaled model of the $25^{\circ} / 55^{\circ}$ cone is calculated for both R5Ch and LENS flow conditions. The calculations are performed by using the direct simulation Monte Carlo (DSMC) method of Bird [1]. Results presented emphasize the sensitivity of the surface quantities (heating, pressure, and skin friction) to model configuration, size, flow conditions, and grid resolution.

\section{RESULTS OF CALCULATIONS FOR SHARP DOUBLE CONES}

Table 1 provides a summary of the free-stream and surface boundary conditions used in the current study. Information concerning model size, configuration, and locations and extent of separation are included in Table 2. Data for the extent of separation are presented in terms of two dimensions: (1) the distance measured along the $\mathrm{x}$-axis of the model and (2) the wetted distance along the surface s. The selection of the grid and numerical parameters involved a series of calculations for each test condition. The grid refinement procedure was influenced by the experience of Refs. 2 and 3, which demonstrated a very sensitive dependence of separation 
TABLE 1. Free-stream and surface ${ }^{a}$ conditions.

\begin{tabular}{lcccccccc}
\hline & \multicolumn{1}{c}{$V_{\infty}}$, & $\rho_{\infty} \times 10^{4}$, & $n_{\infty} \times 10^{-22}$, & $T_{\infty}$, & $p_{\infty}$, & & \multicolumn{2}{c}{$T_{W}}$, \\
$\mathrm{m}^{-3}$ & $\mathrm{~kg} / \mathrm{m}^{3}$ & $\mathrm{~K}$ & $\mathrm{~N} / \mathrm{m}^{2}$ & Gas & $M_{\infty}$ & $\mathrm{K}$ \\
\hline ONERA R5Ch $^{\mathrm{b}}$ & 1418.7 & 4.303 & 0.895 & 51.0 & 6.30 & Air & 9.91 & 293.0 \\
CUBRC LENS-A $^{\mathrm{c}}$ & 2713.6 & 6.808 & 1.463 & 194.1 & 39.21 & $N_{2}$ & 9.56 & 297.8 \\
CUBRC LENS-B & 2657.9 & 7.782 & 1.673 & 198.9 & 45.93 & $N_{2}$ & 9.25 & 293.0 \\
CUBRC LENS-C & 2713.6 & 8.647 & 1.858 & 194.1 & 49.80 & $N_{2}$ & 9.56 & 293.0 \\
\hline
\end{tabular}

${ }^{a}$ Diffuse with full thermal accommodation.

${ }^{\mathrm{b}}$ Denotes nominal test conditions.

${ }^{c} \mathrm{~A}$ denotes actual test conditions, $\mathrm{B}$ denotes nominal pretest conditions, and $\mathrm{C}$ denotes fictitious conditions (adjustment of density) to achieve a specific Reynolds number.

TABLE 2. Results of DSMC calculations for sharp double cones.

\begin{tabular}{|c|c|c|c|c|c|c|c|c|c|}
\hline \multicolumn{3}{|c|}{ Cone parameters ${ }^{a}$} & \multirow[b]{2}{*}{ Grid $^{b}$} & \multirow{2}{*}{$\begin{array}{c}\text { Test } \\
\text { condition }\end{array}$} & \multirow[b]{2}{*}{$\operatorname{Re}_{\infty, d}$} & \multirow{2}{*}{$\begin{array}{c}\text { Separation } \\
x_{S}, \mathrm{~mm}\end{array}$} & \multirow{2}{*}{$\begin{array}{c}\text { Reattachment } \\
x_{R}, \mathrm{~mm}\end{array}$} & \multirow[b]{2}{*}{$\Delta \mathrm{x} / \mathrm{L}_{1}$} & \multirow[b]{2}{*}{$\Delta \mathrm{s} / \mathrm{L}_{1}$} \\
\hline Angles & $L_{1}, \mathrm{~mm}$ & $\mathrm{~d}, \mathrm{~mm}$ & & & & & & & \\
\hline $25^{\circ} / 65^{\circ}$ & 25.0 & 66.4 & $\mathrm{~F}$ & $\mathrm{R} 5 \mathrm{Ch}$ & 12360 & 13.86 & 25.95 & 0.484 & 0.700 \\
\hline $25^{\circ} / 65^{\circ}$ & 25.0 & 66.4 & I & $\mathrm{R} 5 \mathrm{Ch}$ & 12360 & 13.86 & 25.87 & 0.480 & 0.692 \\
\hline $25^{\circ} / 65^{\circ}$ & 25.0 & 66.4 & $\mathrm{C}$ & $\mathrm{R} 5 \mathrm{Ch}$ & 12360 & 14.34 & 25.45 & 0.444 & 0.631 \\
\hline $25^{\circ} / 65^{\circ}$ & 25.0 & 66.4 & $\mathrm{VC}$ & $\mathrm{R} 5 \mathrm{Ch}$ & 12360 & 15.50 & 24.38 & 0.355 & 0.479 \\
\hline $25^{\circ} / 65^{\circ}$ & 30.1 & 80.0 & $\mathrm{C}$ & $\mathrm{R} 5 \mathrm{Ch}$ & 14880 & 16.72 & 31.14 & 0.478 & 0.691 \\
\hline $25^{\circ} / 65^{\circ}$ & 40.0 & 106.3 & $\mathrm{C}$ & $\mathrm{R} 5 \mathrm{Ch}$ & 19775 & 20.80 & 42.33 & 0.538 & 0.786 \\
\hline $25^{\circ} / 65^{\circ}$ & 45.5 & 121.0 & $\mathrm{C}$ & $\mathrm{R} 5 \mathrm{Ch}$ & 22500 & 21.41 & 50.63 & 0.642 & 0.969 \\
\hline $25^{\circ} / 65^{\circ \mathrm{c}}$ & 50.0 & 132.9 & I & $\mathrm{R} 5 \mathrm{Ch}$ & 24719 & 21.31 & 59.43 & 1.109 & 1.198 \\
\hline $25^{\circ} / 55^{\circ}$ & 25.8 & 66.4 & I & $\mathrm{R} 5 \mathrm{Ch}$ & 12360 & 21.17 & 25.36 & 0.162 & 0.229 \\
\hline $25^{\circ} / 55^{\circ}$ & 25.8 & 66.4 & $\mathrm{I}$ & LENS-A & 9730 & 21.75 & 24.61 & 0.111 & 0.154 \\
\hline $25^{\circ} / 55^{\circ}$ & 25.8 & 66.4 & I & LENS-C & 12360 & 21.45 & 24.74 & 0.127 & 0.179 \\
\hline $25^{\circ} / 55^{\circ \mathrm{d}}$ & 101.6 & 261.8 & I & LENS-A & 38340 & 80.02 & 99.87 & 0.196 & 0.265 \\
\hline $25^{\circ} / 55^{\circ}$ & 101.6 & 261.8 & I & LENS-B & 42150 & 80.01 & 100.10 & 0.198 & 0.269 \\
\hline $25^{\circ} / 55^{\circ}$ & 101.6 & 261.8 & $\mathrm{C}$ & LENS-B & 42150 & 80.60 & 99.17 & 0.182 & 0.246 \\
\hline $25^{\circ} / 55^{\circ}$ & 101.6 & 261.8 & $\mathrm{VC}$ & LENS-B & 42150 & 84.00 & 97.81 & 0.136 & 0.186 \\
\hline
\end{tabular}

${ }^{a} L_{1}$ is wetted length of first cone and $\mathrm{d}$ is maximum diameter.

${ }^{b}$ Qualitative description of grid resolution: F-fine, I-intermediate, C-coarse, and VC-very coarse.

${ }^{c}$ From Ref. 3.

${ }^{\mathrm{d}}$ Only case for which experimental measurements have been made-data to be released later.

extent to grid refinement. The Reynolds number is based on free-stream conditions with a characteristic length $\mathrm{d}$, the maximum diameter of the model. For the R5Ch flow conditions, the Sutherland viscosity has been used in defining the Reynolds number to be consistent with experimentally reported values. For the LENS conditions, the variable hard sphere model for viscosity (temperature exponent of 0.75 and a reference temperature of $300 \mathrm{~K}$ ) is used in specifying Reynolds number.

\section{$25^{\circ} / 65^{\circ}$ Cones at Mach 9.9 Air Flow-R5Ch Conditions}

Calculations presented in this section are an extension of those reported in Refs. 2 and 3 , where the flow about a sharp double-cone model $\left(25^{\circ} / 65^{\circ}\right)$ with a maximum diameter of $132.893 \mathrm{~mm}$ was calculated with both DSMC and Navier Stokes codes for Reynolds numbers ranging from 24719 to 247. This Reynolds number range was achieved by using the $\mathrm{R} 5 \mathrm{Ch}$ nominal free-stream flow conditions (highest Reynolds number) and then parametrically reducing the free-stream density. The current results are those for smaller scale models with diameters between 66.4 and $121.0 \mathrm{~mm}$. The maximum diameter of the current model configuration that can be tested in the R5Ch wind tunnel is near $70 \mathrm{~mm}$, or about half of the model size used in the previous studies. The configuration is such that the length of the first and second cones are equal $\left(L_{1}=L_{2}\right.$, Fig. 1a).

Figures 1 and 2 present representative results of the calculations. The nature of the shock interactions is demonstrated in Fig. 1a by using the fine grid results for the 66.4-mm-diameter model, a model size that the ONERA R5Ch wind tunnel should be able to accommodate. Selected Mach contours are shown where a large subsonic region, indicated by the darker shading, is located in front of the second cone. Locations for 


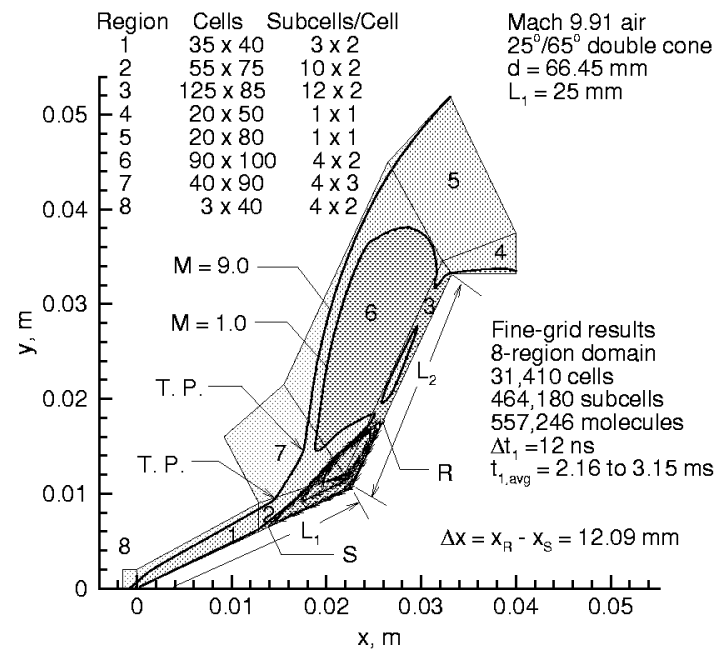

Fig. 1a. Flow structure.

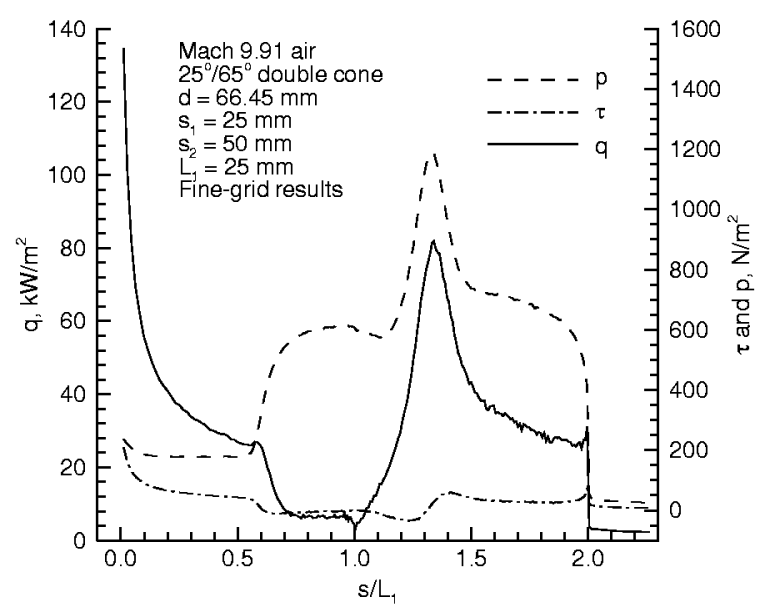

Fig. 1b. Surface results.

FIGURE 1. Fine-grid results for $25^{\circ} / 65^{\circ}$ double cone at $\mathrm{R} 5 \mathrm{Ch}$ flow conditions; $\mathrm{d}=66.45 \mathrm{~mm}$.

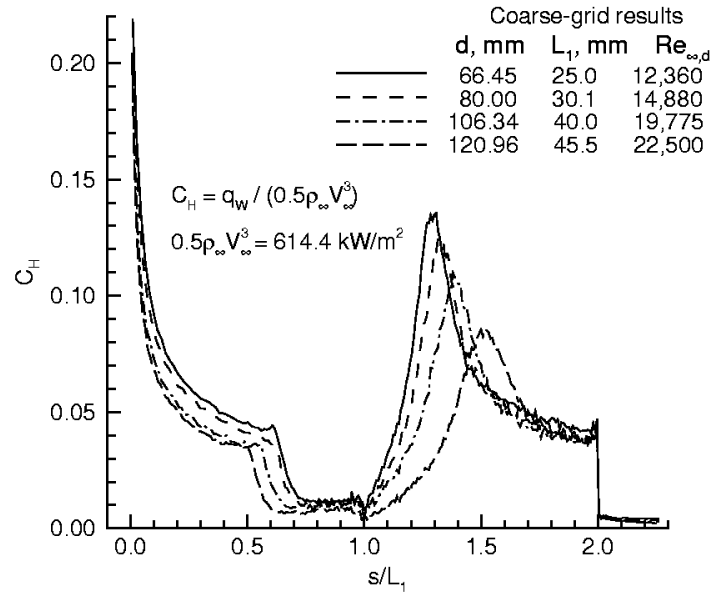

Fig. 2a. Heat-transfer coefficient.

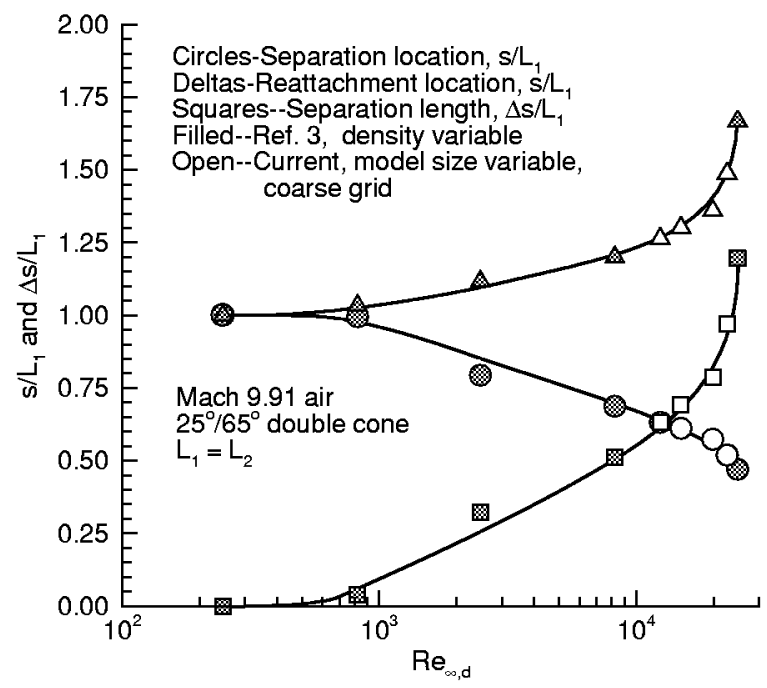

Fig. 2b. Separation data.

FIGURE 2. $25^{\circ} / 65^{\circ}$ double-cone results at $\mathrm{R} 5 \mathrm{Ch}$ flow conditions.

flow separation and reattachment along the surface are denoted by $\mathrm{S}$ and $\mathrm{R}$, respectively. Also evident is the influence of the separation shock on the oblique shock that is produced by the first cone, resulting in a triple point (T. P.) followed by a stronger transmitted shock that interacts with the stronger bow shock of the second cone-creating a second triple point. These shock/shock and shock/boundary layer interactions are induced by the larger cone and produce a significant separation region characterized by a single vortex embedded within the subsonic region near the intersecting cones. The general flow structure evident for the 66.45 -mm-diameter model is that found for the larger $25^{\circ} / 65^{\circ}$ models. However, when the model diameter is increased to $132.9 \mathrm{~mm}$ (results from Ref. 3 and included in Table 2), secondary vortices were evident, and a Navier-Stokes computation indicated some unsteadiness (small oscillations of separation location). Undoubtedly, the flow would become 
unsteady for larger models, as is demonstrated by the rapid growth of the extent of separation presented in Fig. 2.

Also included in Fig. 1a is information concerning the computational domain, which consisted of eight arbitrary regions. Each region is subdivided into cells, and the cells in selected regions are subdivided into subcells to enhance the spatial resolution used to select collision partners. Time step information for region one and the time interval for which the time-averaged results were obtained are included in Fig. 1a. Since the computational regions were not run with necessarily the same time step, it was essential that steady state conditions be established before generating the final time-averaged results. Steady state was assumed to occur when the total molecules used in the simulation, average molecules in each region, and locations and size of the separation region became constant when sampled over some significant time interval.

Figure $1 \mathrm{~b}$ presents the corresponding surface results-heating rate, pressure, and skin friction-for the 66.45mm-diameter model. Results are for the fine-grid solution, the only condition for which the surface results and extent of separation indicate grid independence (Table 2)-fine and intermediate grid results are the same for surface quantities. (Additional grid refinement is necessary to determine if the remaining intermediate grid results are grid independent.) The qualitative features are consistent with experimental measurements [4] for laminar separated flows. First, the separation position is in close agreement with the location of the first inflection point (maximum slope) of the initial pressure rise and the location where the heat transfer rate decreases significantly with respect to the single cone results. Second, the pressure reaches a plateau for a significantly large separation region, while the heat transfer is significantly reduced. Third, at or preceding the intersection of the two cones, the heat transfer experiences a minimum and then increases rapidly, as does the pressure, with increasing distance along the second cone.

Figure 2 presents results that highlight the effect of model size or Reynolds number on the calculation where the data presented are for coarse grids (comparable grid resolution for the four cases). Heat transfer coefficient results for the four model sizes investigated (Fig. 2a) show the expected trend of decreasing magnitude with increasing Reynolds number. Also, as expected for laminar flow, the extent of separation increases (earlier separation and delayed reattachment), as can be inferred from Fig. 2a, and is explicitly shown by the nondimensional separation data included in Table 2.

The sensitivity of the extent of separation to Reynolds number is presented in Fig. 2b, where the current data (coarse grid results) are those obtained by varying the model size. The data from Ref. 3 were obtained by varying the free-stream conditions (density) for a fixed model size $(\mathrm{d}=132.89 \mathrm{~mm})$. The two data sets show a consistent trend: the extent of separation increasing with Reynolds number and a very rapid increase in separation near a Reynolds number of 25000 . For the conditions investigated, the calculations show that separation persists for Reynolds numbers as low as about 800 .

\section{$25^{\circ} / 55^{\circ}$ Cone With a Diameter of $66.45 \mathbf{~ m m}-\mathbf{R} 5 \mathrm{Ch}$ and LENS Conditions}

To clarify the effect of different experimental test conditions on surface and flow-field features, a common model is used for making calculations at both ONERA R5Ch and LENS nominal test conditions. The model configuration is one that has been used in the CUBRC tests, but the maximum model diameter is $66.45 \mathrm{~mm}$ rather than the $261.8-\mathrm{mm}$-diameter model tested. Figure 3 presents information concerning flow-field features and computational parameters, while Fig. 4 provides information concerning surface results for heating and pressure. Table 2 provides information concerning the location and extent of separation.

A $10^{\circ}$ reduction in the second cone half angle has a very pronounced impact on the flow-field features for the R5Ch nominal test conditions, as is clearly evident when the results of Fig. 3a are compared with those of Fig. 1a. Marked differences are evident for the nature of the shock/shock and shock/boundary layer interactions, size and location of the subsonic region, and size of the separation zone. When the calculation is made for the LENS-A test conditions (Fig. 3b), the shock layer disturbance is slightly smaller, and the size of the subsonic region and the extent of separation are noticeably reduced when compared with the results for the $\mathrm{R} 5 \mathrm{Ch}$ flow conditions. The corresponding surface results for heating and pressure coefficients are included in Fig. 4. Data are also included for a flow condition referred to as LENS-C, where an adjustment to the density of the LENS-A nominal test condition is made to produce a larger free-stream Reynolds number, a value equal to that of the R5Ch test condition. The nondimensional heating and pressure results presented in Fig. 4 show to what extent the distributions are consistent-very good agreement for pressure with the exception of the strong interaction region, while that for heating is more qualitative. For the surface region where separation occurs, the heating and pressure coefficient values are much larger for the LENS test conditions than those for 
the $\mathrm{R} 5 \mathrm{Ch}$ conditions. Of course, the dimensional heating and pressure values are much larger for the LENS conditions, about an order of magnitude difference in heating rates. The effect of increasing the free-stream density of the LENS-A condition, to produce the LENS-C conditions (same Reynolds number as the R5Ch case), is clearly evident in the $C_{H}$ distributions and extent of separation (Table 2) but has a minor effect on the $C_{p}^{\prime}$ distribution. However, the present results for the surface coefficients (friction not shown) indicate that the Reynolds number is not the only controlling parameter.

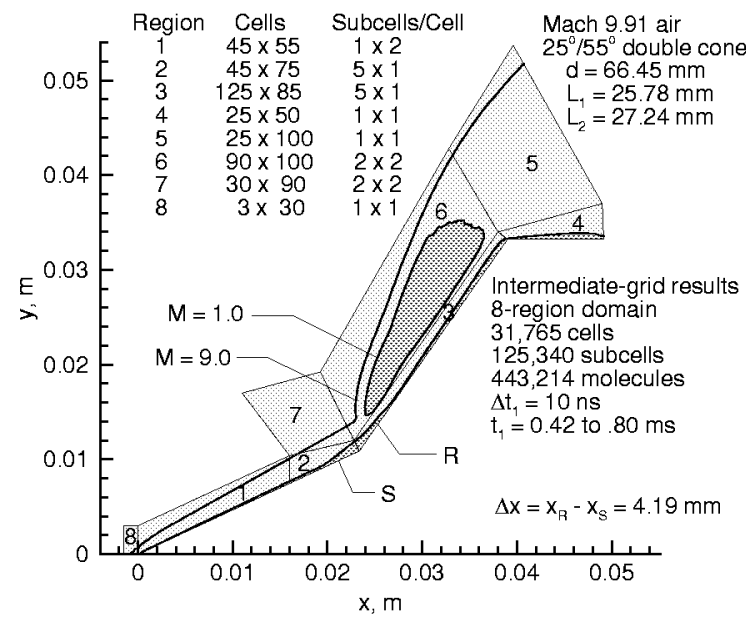

Fig. 3a. R5Ch conditions.

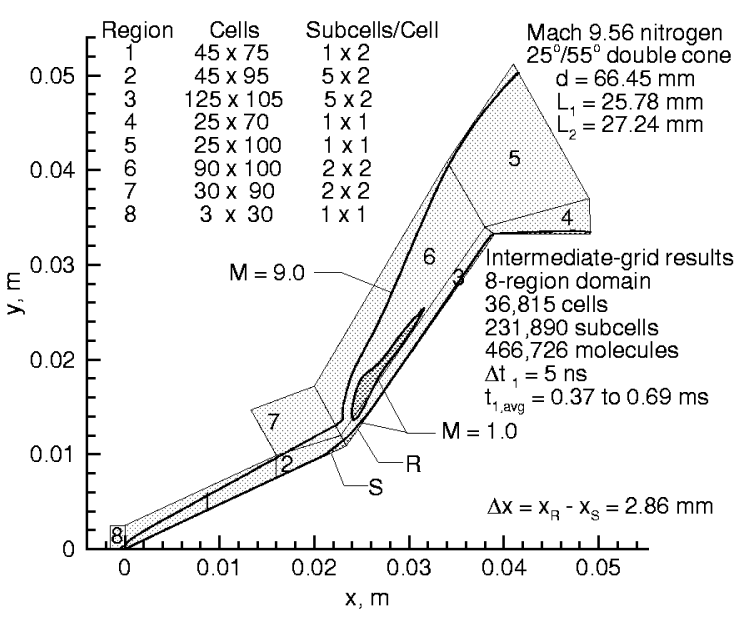

Fig. 3b. LENS-A conditions.

FIGURE 3. Flow structure for $25^{\circ} / 55^{\circ}$ double cone; $\mathrm{d}=66.45 \mathrm{~mm}$.

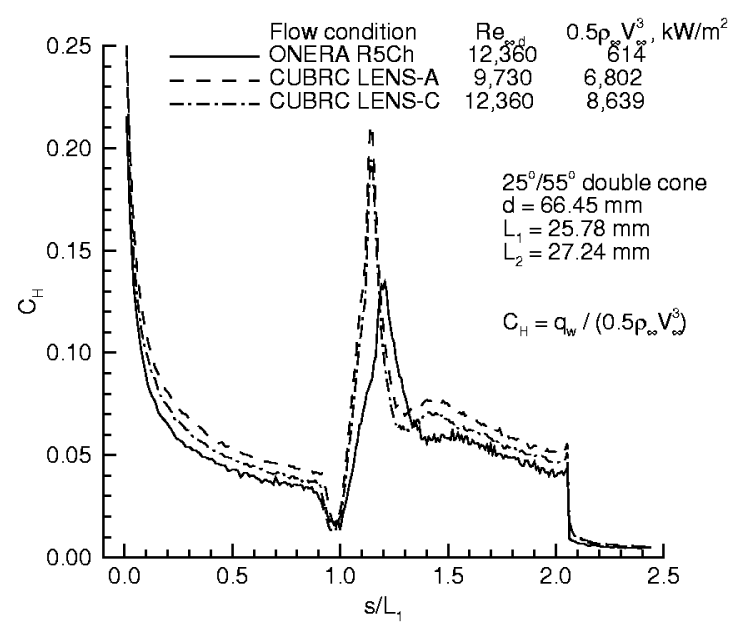

Fig. 4a. Heat-transfer coefficient.

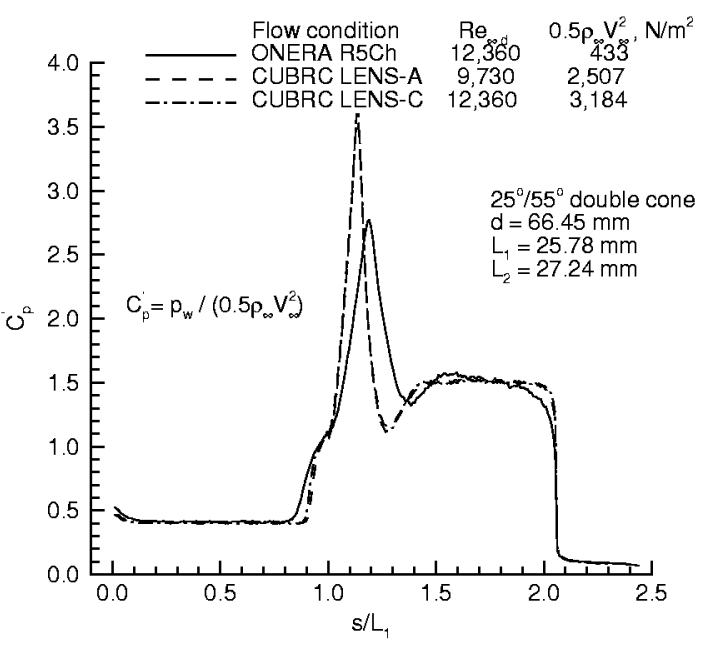

Fig. 4b. Pressure coefficient.

FIGURE 4. Surface results as a function of test conditions for $25^{\circ} / 55^{\circ}$ double cone; $\mathrm{d}=66.45 \mathrm{~mm}$. 


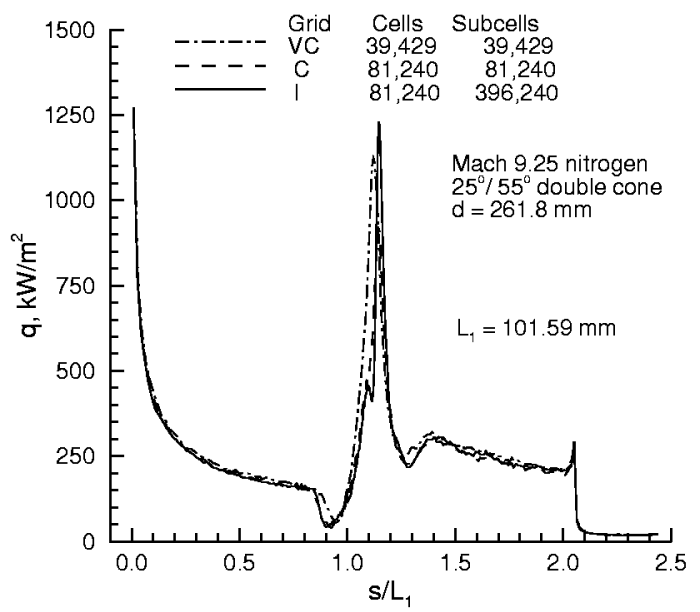

Fig. 5a. Heating-rate distributions.

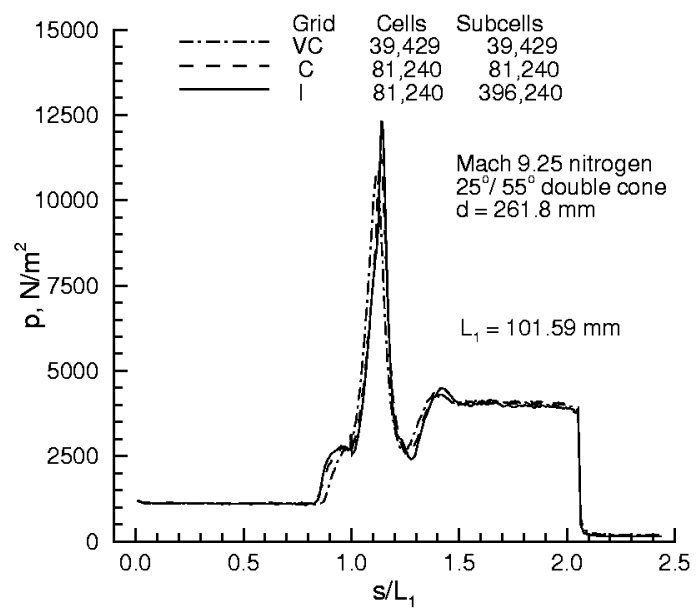

Fig. 5b. Pressure distributions.

FIGURE 5. Effect of grid on surface results for $25^{\circ} / 55^{\circ}$ double cone; $\mathrm{d}=261.8 \mathrm{~mm}$ and LENS-B flow conditions.

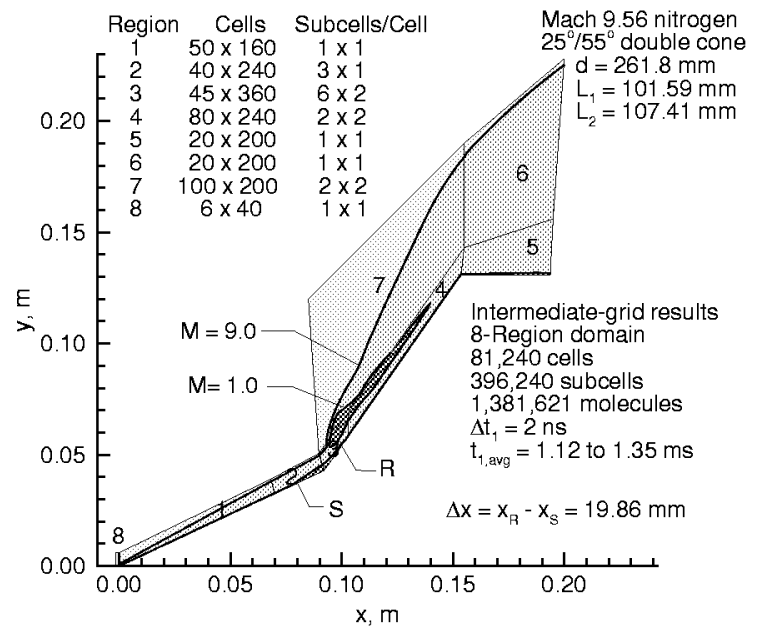

Fig. 6a. Flow structure.

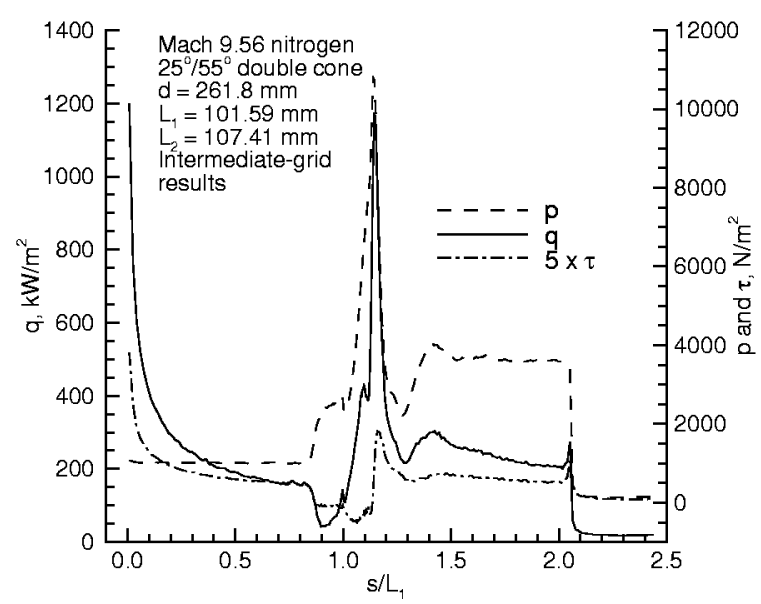

Fig. 6b. Surface quantities.

FIGURE 6. Intermediate-grid results for $25^{\circ} / 55^{\circ}$ double cone; $\mathrm{d}=261.8 \mathrm{~mm}$ and LENS-A flow conditions.

\section{$25^{\circ} / 55^{\circ}$ Cone at Mach 9.6 Nitrogen Flow- LENS Conditions}

This section focuses on results for the CUBRC LENS flow conditions where the maximum model diameter is $261.8 \mathrm{~mm}$. The initial calculations were made for pretest nominal conditions-denoted as LENS-B test condition. A grid sensitivity study was conducted, and the results of this study, as it impacts separation and reattachment locations, are listed in Table 2 . The sensitivity on heating and pressure distributions is presented in Fig. 5. The finest grid used in this exercise (described as intermediate I, since grid independence was not demonstrated) was then used to make a calculation for the actual test condition (LENS-A), and selected results are presented in Fig. 6. The general features of the shock layer structure are given in Fig. 6a where selected Mach contours are included, along with details of the numerical parameters used in the simulation. The impact 


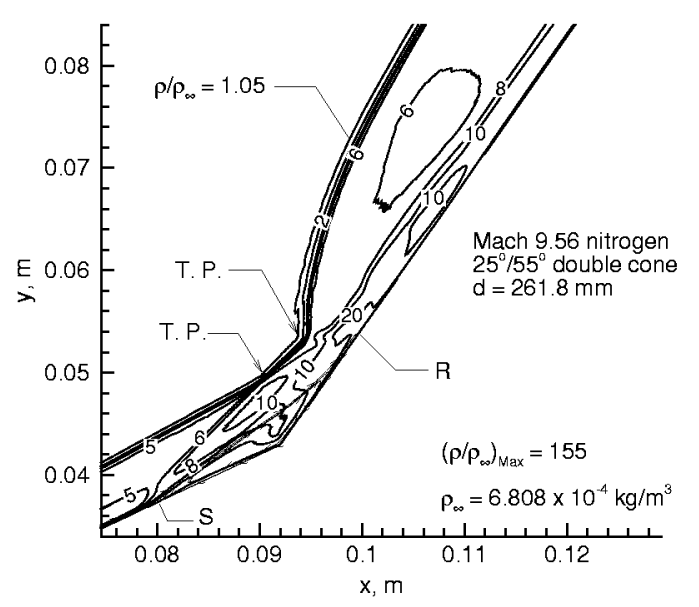

Fig. 7a. Density contours.

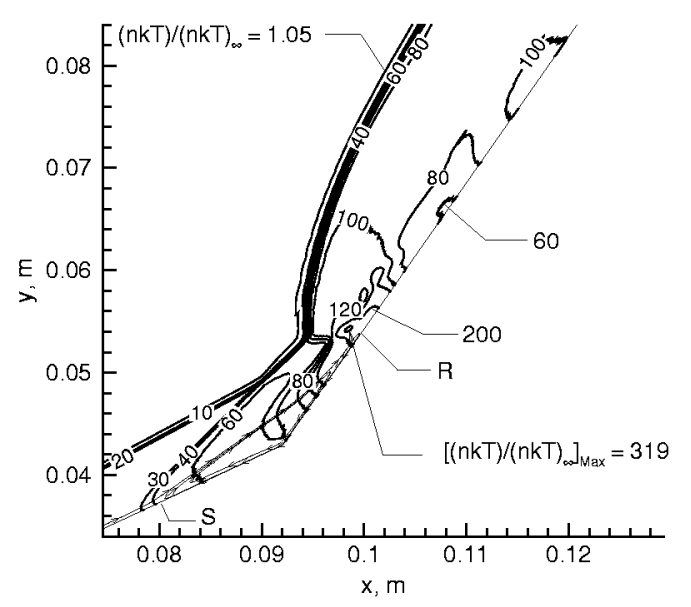

Fig. 7b. Scalar pressure contours.

FIGURE 7. Interaction region results for $25^{\circ} / 55^{\circ}$ double cone; $\mathrm{d}=261.8 \mathrm{~mm}$ and LENS-A flow conditions.

of model size and flow conditions on shock layer features can be observed by comparing these results with those given in Fig. 3. Values for the surface quantities are shown in Fig. 6b. For the surface pressure distribution, the calculated values outside the region influenced by the shock/boundary layer interactions are in close agreement with the inviscid cone values (Ref. 5) of $948 \mathrm{~N} / \mathrm{m}^{2}$ along the $25^{\circ}$ cone and $3710 \mathrm{~N} / \mathrm{m}^{2}$ along the $55^{\circ}$ cone. Opportunities will exist for comparison with the experimental measurements that have been completed when the CUBRC data are released.

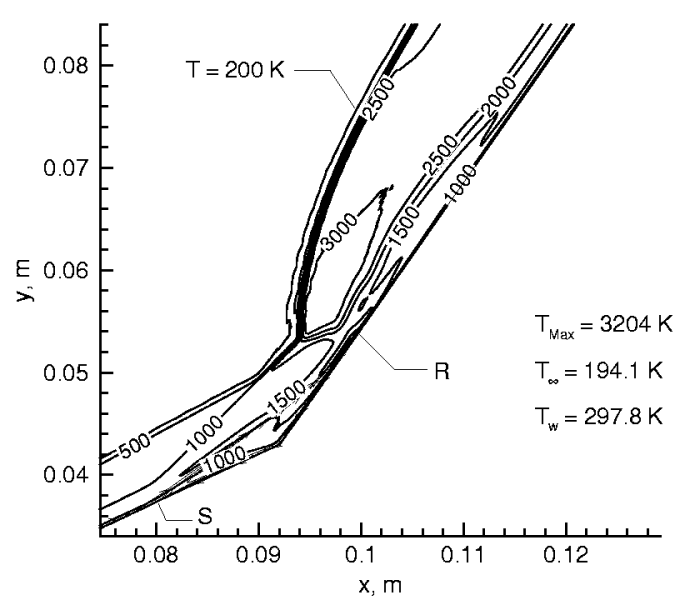

Fig. 8a. Overall kinetic temperature contours.

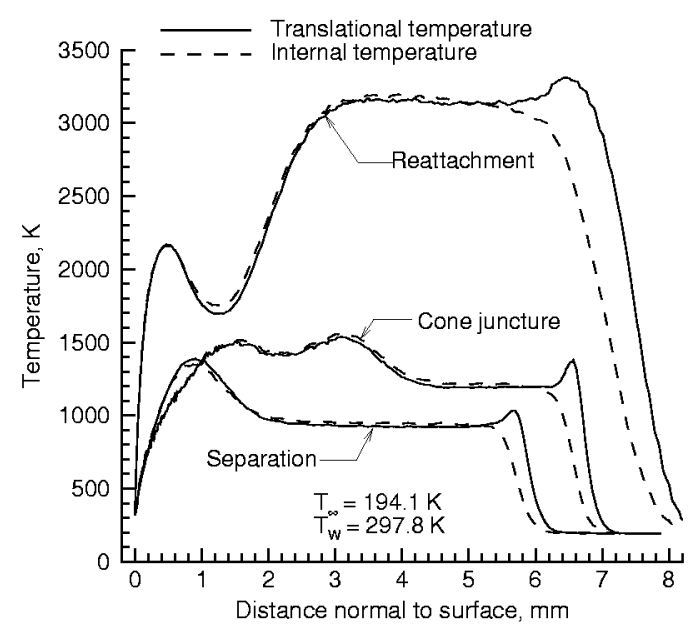

Fig. 8b. Temperature profiles.

FIGURE 8. Interaction region results for $25^{\circ} / 55^{\circ}$ double cone; $\mathrm{d}=261.8 \mathrm{~mm}$ and LENS-A flow conditions.

Figures 7 and 8 present details concerning the flow-field structure for the CUBRC test case where the focus is on the interaction region. From the density and scalar pressure contours presented in Figs $7 \mathrm{a}$ and $7 \mathrm{~b}$, respectively, one gets an appreciation of the compression and large gradients that occur near reattachment- 
maximum values for density equal 155 times free-stream and maximum scalar pressure (displaced a substantial distance from the surface) equal 319 times free stream. The overall kinetic temperature, denoted by $\mathrm{T}$ in Fig. $8 \mathrm{a}$, experiences a maximum value of about $1000 \mathrm{~K}$ along most of the first cone, but values as large as $3200 \mathrm{~K}$ occur along the second cone. (For comparison, the corresponding maximum values for the calculation presented in Fig. 1 are 30, 190, and $974 \mathrm{~K}$, respectively.) More details concerning the thermal structure of the flow are presented in Fig. 8b, where translational and internal temperature (rotational and vibrational contributions, see Ref. 1) profiles are shown. These temperature profiles are approximately normal to the surface, and results are included for three surface locations: separation, cone juncture (normal to the $25^{\circ}$ cone), and reattachment. The current results show that the nonequilibrium effects are confined primarily to the outer bow shock crossings with close agreement between translational and internal temperatures for the remainder of the shock layer. Evident from the flow structure results are the existences of two triple points, a region of separated flow with a single vortex, two subsonic regions along the second cone that sandwich a supersonic region, and a flow that for the most part is in thermal equilibrium. Reattachment occurs subsonically.

\section{CONCLUDING REMARKS}

Results of a computational study are presented for Mach 10 flow about sharp double cones where the combination of model configurations, size, and flow conditions produce a significant range of shock/shock and shock/boundary layer interactions. The computations are made with the direct simulation Monte Carlo (DSMC) method, hence, low Reynolds number flows. The results presented provide insight into the nature of the shock interactions, their impact on surface quantities, and the sensitivity of the results to computational parameters for flow conditions that can be produced in current ground-based facilities. Extent of separation as a function of free-stream Reynolds number is demonstrated, and the current results are shown to be consistent with previous calculations. Computations are made for a common model size and configuration at conditions that can be produced in a hypersonic cold flow wind tunnel and a much higher enthalpy impulse facilitycontrasting computational results for substantially different flow conditions. Opportunities should exist for comparing the current results with experimental measurements for surface heating and pressure distributions.

\section{ACKNOWLEDGMENTS}

The author wishes to acknowledge the assistance of Michael Holden of CUBRC for providing information regarding the model configuration and flow conditions used in the LENS tests, both pretest and actual test conditions. Also, appreciation is expressed to T. Pot and B. Chanetz of ONERA, Chalais-Meudon, for conducting exploratory tests in R5Ch to establish a model size for which future tests can be performed.

\section{REFERENCES}

1. Bird, G., Molecular Gas Dynamics and the Direct Simulation of Gas Flows, Oxford: Clarendon Press, 1994.

2. Moss, J., and Olejniczak, J., Shock-Wave/Boundary-Layer Interactions in Hypersonic External Flows, AIAA Paper 98-2668, 1998.

3. Moss, J., Olejniczak, J., Chanetz, B., and Pot, T., Hypersonic Separated Flows at Low Reynolds Number Conditions, Rarefied Gas Dynamics, Vol. II, Toulouse: Cepadues-Editions, 1999, pp. 617-624.

4. Needham, D., and Stollery, J., Boundary Layer Separation in Hypersonic Flow, AIAA Paper 66-455, 1966.

5. Ames Research Staff, Equations, Tables, and Charts for Compressible Flow, NACA Report 1135, 1953. 
Public reporting burden for this collection of information is estimated to average 1 hour per response, including the time for reviewing instructions, searching existing data sources, gathering and maintaining the data needed, and completing and reviewing the collection of information. Send comments regarding this burden estimate or any other aspect of this collection of information, including suggestions for reducing this burden, to Washington Headquarters Services, Directorate for Information Operations and

Reports, 1215 Jefferson Davis Highway, Suite 1204, Arlington, VA 22202-4302, and to the Office of Management and Budget, Paperwork Reduction Project (0704-0188), Washington, DC 20503.

\begin{tabular}{|l|l|l}
\hline 1. AGENCY USE ONLY (Leave blank) & $\begin{array}{l}\text { 2. REPORT DATE } \\
\text { August } 2000\end{array}$ & $\begin{array}{l}\text { 3. REPORT TYPE AND DATES COVERED } \\
\text { Technical Memorandum }\end{array}$ \\
\hline
\end{tabular}

\begin{tabular}{l|l} 
4. TITLE AND SUBTITLE & 5. FUNDING NUMBERS \\
DSMC Simulations of Shock Interactions About Sharp Double Cones
\end{tabular}

DSMC Simulations of Shock Interactions About Sharp Double Cones

WU 242-80-01-01

\author{
6. AUTHOR(S) \\ James N. Moss
}

7. PERFORMING ORGANIZATION NAME(S) AND ADDRESS(ES)

8. PERFORMING ORGANIZATION REPORT NUMBER

NASA Langley Research Center

Hampton, VA 23681-2199

L-18013

9. SPONSORING/MONITORING AGENCY NAME(S) AND ADDRESS(ES)

10. SPONSORING/MONITORING AGENCY REPORT NUMBER

National Aeronautics and Space Administration

Washington, DC 20546-0001

NASA/TM-2000-210318

\title{
11. SUPPLEMENTARY NOTES
}

12a. DISTRIBUTION/AVAILABILITY STATEMENT

12b. DISTRIBUTION CODE

Unclassified-Unlimited

Subject Category 34 Distribution: Nonstandard

Availability: NASA CASI (301) 621-0390

13. ABSTRACT (Maximum 200 words)

This paper presents the results of a numerical study of shock interactions resulting from Mach 10 flow about sharp double cones. Computations are made by using the direct simulation Monte Carlo (DSMC) method of Bird. The sensitivity and characteristics of the interactions are examined by varying flow conditions, model size, and configuration. The range of conditions investigated includes those for which experiments have been or will be performed in the ONERA R5Ch low-density wind tunnel and the Calspan-University of Buffalo Research Center (CUBRC) Large Energy National Shock (LENS) tunnel.

\section{SUBJECT TERMS}

Hypersonic, low density, DSMC computations, shock/shock interactions, shock/boundary layer interactions

\begin{tabular}{|l|c|}
\hline $\begin{array}{l}\text { 17. SECURITY CLASSIFICATION } \\
\text { OF REPORT } \\
\text { Unclassified }\end{array}$ & $\begin{array}{c}\text { 18. SECURITY CLASSIFICATION } \\
\text { OF THIS PAGE } \\
\text { Unclassified }\end{array}$ \\
\hline
\end{tabular}

NSN 7540-01-280-5500 OF ABSTRACT
19. SECURITY CLASSIFICATION

Unclassified
15. NUMBER OF PAGES 13

16. PRICE CODE A03

20. LIMITATION OF ABSTRACT

UL 